\title{
Comparative Analysis of the Effects of False Low- Price Marketing Strategy on Multiple Platforms
}

\author{
Wanting $\mathrm{He}^{1}{ }^{*}$, Xixi Zhu' ${ }^{2}$, Lianghui Zhao ${ }^{1}$ \\ ${ }^{1}$ School of Economics and Management, Wuyi University, Jiangmen 529020, Guangdong Province, China \\ ${ }^{2}$ Hochschule Anhalt, Bernburg 06406, Germany
}

*Corresponding author: Wanting He, 2514896024@qq.com

\begin{abstract}
In order to make full use of the characteristics of commodity prices, merchants on e-commerce platforms have adopted the low-price marketing strategy. Regular promotional discounts can bring new vitality to the commodity sales market, but extreme discount marketing methods would lead to serious impacts on the sales of competing products, thus affecting the stable development of the online shopping market. The sales data of four electrical products using the false lowprice marketing strategy on three e-commerce platforms (Taobao, JD, and Amazon) were used in this study. The sales data from different e-commerce platforms and different time periods were analyzed, and one-way ANOVA was used on the factors affecting the effect of marketing strategy. The results showed that there is a significant difference between the direct marketing of high-priced products and low-priced products on Taobao; the difference between the marketing effects of high-priced products and mid-priced products on JD and Amazon is significant. This analysis would help businesses formulate reasonable marketing strategies and promote the stable development of the online shopping market.
\end{abstract}

Keywords: E-commerce platform; False low price; Marketing strategy; Marketing effect

Publication date: December 2021; Online publication: December 31, 2021

\section{Introduction}

With the improvement of living standards and the rapid development of the internet, e-commerce has penetrated into all aspects of life, and people are more inclined to shop online. Online shopping is very different from offline shopping. It reduces consumers' consumption experience and changes the influencing factors of consumers' purchase decisions. Merchants have tried various online marketing methods to improve commodity sales and commodity browsing. Price factor is the focal point of many merchants. In each e-commerce platform, there are regulations and rules for the changes of SKU price. A significant change in SKU price would have a serious impact on the store. Recently, under the corresponding management rules of the platform, some businesses sell goods by marking false low prices or issuing exclusive coupons for individual SKUs. These methods can ensure that the prices are still within the original price range, and by marking the prices after discount on the publicity page would attract more consumers.

\section{Literature review}

In the whole e-commerce marketing process, commodity price is a factor of great concern to merchants and consumers. In the formulation of marketing strategies, the method through commodity price strategy has been widely used by merchants. The use of commodity price related marketing strategies by merchants can weaken consumers' sensitivity to commodity prices in the purchase process and guide consumers to make purchase decisions. 
Scholars have conducted numerous studies on consumers' sensitivity to price in the purchase process. Enrique and Sergio studied the promotion of goods using lower prices and analyzed its impact on consumers' search behavior, perceived value, and purchase intention ${ }^{[1]}$. Sérgio and Helder pointed out that pricing is a difficult entity to estimate, and pricing directly affects the income of enterprises. Exploring the response of consumers to prices is effective for enterprises in carrying out marketing. Price sensitivity reflects consumers' feelings in paying a certain price for a certain product ${ }^{[2]}$. Sun Xiaodong, Tian Peng, and Zhao Li proposed that the heterogeneity of consumers lies in the sensitivity of consumers to price and quality; they explained that different pricing strategies depend on the switching cost of consumers ${ }^{[3]}$. Zhang Xianglan and Guo Jing pointed out that commodity prices have an important impact on consumers' behavior. Price is the direct standard for consumers to measure the value of commodities. Therefore, consumers' psychology toward price would affect their purchase behavior. Consumers have habitual psychology, sensitive psychology, receptive psychology, tendentious psychology, and rebellious psychology ${ }^{[4]}$. Zhou Bin and Wang Xuefei believe that consumers are very sensitive to price changes, and consumers are more sensitive to a rise in price rather than its fall ${ }^{[5]}$.

Many scholars have been paying attention to the price marketing of goods in the process of commodity marketing. They have been exploring from various aspects, such as consumers' habits, price sensitivity, and discount tolerance; moreover, they have also proposed some research methods for discount marketing. This study analyzes the commodity marketing effect of false low price marketing strategy adopted by three platforms and compares the marketing effect of this strategy in different platforms and different price ranges.

\section{Data acquisition}

Four electrical products that have adopted a false low-price marketing strategy were found on Taobao, JD, and Amazon. The sales data of the products are shown in Table 1. This study used Python to crawl the monthly sales, cumulative reviews, collections, ratings, and other data of these products.

Table 1. Product information

\begin{tabular}{ccccc}
\hline Taobao & Massager & Lenovo & Printer & Projector \\
\hline Page price $(¥)$ & 48 & 720 & 69 & 139 \\
Sale price $(¥)$ & 219 & 1580 & 499 & Camera \\
\hline JD & Rice cooker & Balance scooter & Vacuum cleaner & 10 \\
\hline Page price $(¥)$ & 79 & 749 & 39 & 1180 \\
Sale price $(¥)$ & 259 & 1329 & Coffee machine & Audio \\
\hline Amazon & Refrigerator & Television & 39.99 & 15.56 \\
Page price $(\$)$ & 99.99 & 109 & 79.99 & 45.05 \\
Sale price $(\$)$ & 179.99 & 399 & &
\end{tabular}

\section{Data analysis}

\subsection{Direct effect marketing analysis}

Sales changes are the most intuitive manifestation of marketing effects. In this study, the commodities with this marketing strategy have been recorded as experimental commodities, and the corresponding same commodities without this marketing strategy have been recorded as comparison commodities. The commodities on Taobao and JD were calculated by their sales growth percentage, while the commodities on Amazon were calculated by the growth percentage of comments, which were compared according to one month and one quarter as time units, respectively, to seek for rules from the comparison results. 
In order to determine the patterns, this study categorized the commodities according to their prices and divided the commodities on each platform into three categories: high-priced commodities, mid-priced commodities, and low-priced commodities.

Table 2. Classification of goods

\begin{tabular}{|c|c|c|c|c|c|c|c|c|c|}
\hline Platform & & Taobao & & & JD & & & mazon & \\
\hline Classification & $\begin{array}{l}\text { High- } \\
\text { priced }\end{array}$ & $\begin{array}{l}\text { Mid- } \\
\text { priced }\end{array}$ & $\begin{array}{l}\text { Low- } \\
\text { priced }\end{array}$ & $\begin{array}{l}\text { High- } \\
\text { priced }\end{array}$ & $\begin{array}{l}\text { Mid- } \\
\text { priced }\end{array}$ & $\begin{array}{l}\text { Low- } \\
\text { priced }\end{array}$ & $\begin{array}{l}\text { High- } \\
\text { priced }\end{array}$ & $\begin{array}{l}\text { Mid- } \\
\text { priced }\end{array}$ & $\begin{array}{l}\text { Low- } \\
\text { priced }\end{array}$ \\
\hline Goods & Lenovo & $\begin{array}{c}\text { Projector } \\
\text { Printer }\end{array}$ & Massager & $\begin{array}{l}\text { Balance } \\
\text { scooter }\end{array}$ & Camera & $\begin{array}{c}\text { Rice } \\
\text { cooker } \\
\text { Vacuum } \\
\text { cleaner }\end{array}$ & $\begin{array}{c}\text { Television } \\
\text { Refrigerator }\end{array}$ & $\begin{array}{l}\text { Coffee } \\
\text { machine }\end{array}$ & Audio \\
\hline
\end{tabular}

The comparison of the sales growth percentage of the experimental commodities and comparison commodities can preliminarily show the effect of the marketing strategy on commodity sales (Table 2). The sales growth percentages of experimental commodities and comparison commodities in different months were calculated and shown in broken-line graphs as follows:

(1) comparison chart of commodity sales growth on Taobao (Figure 1, Figure 2, Figure 3, and Figure 4);

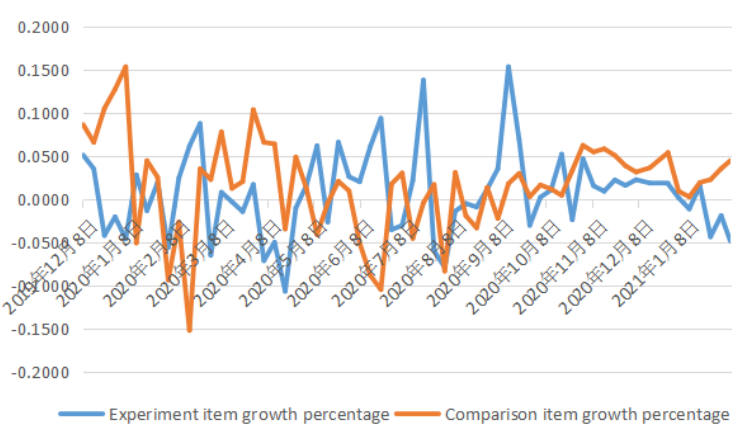

Figure 1. Massager

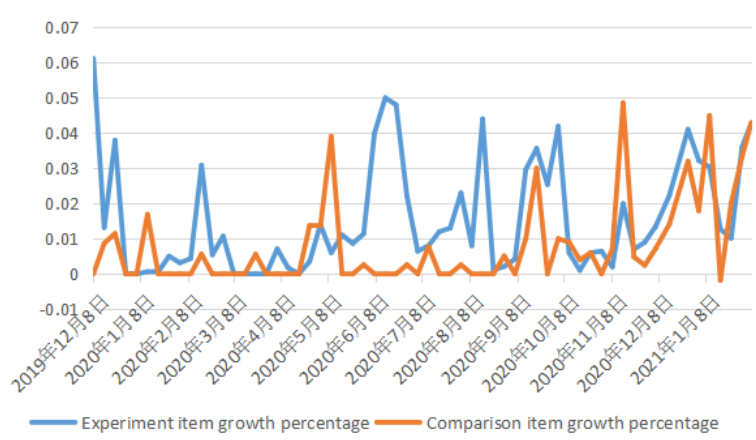

Figure 3. Printer

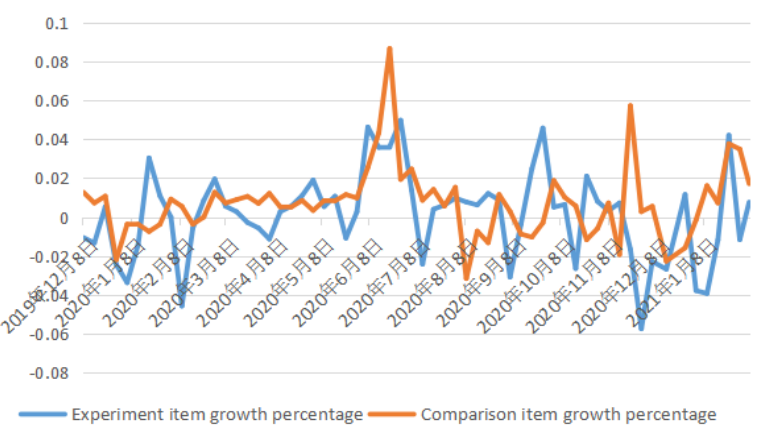

Figure 2. Lenovo

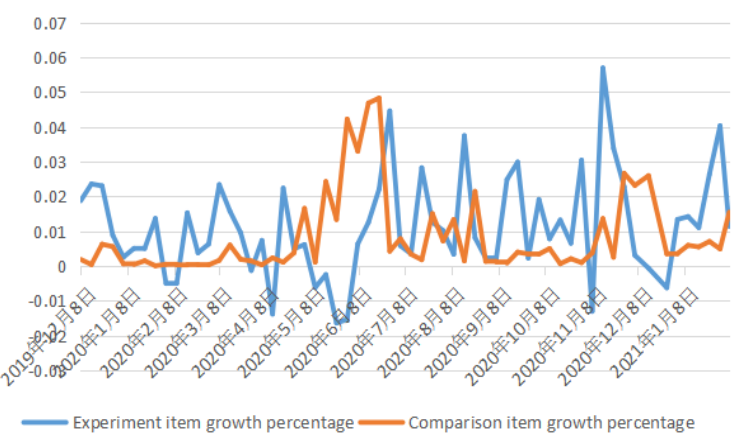

Figure 4. Projector 
(2) comparison chart of commodity sales growth on JD (Figure 5, Figure 6, Figure 7, and Figure 8);

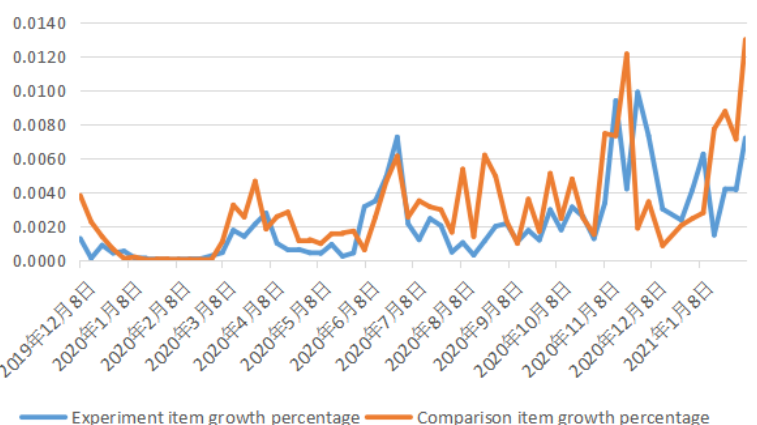

Figure 5. Rice cooker

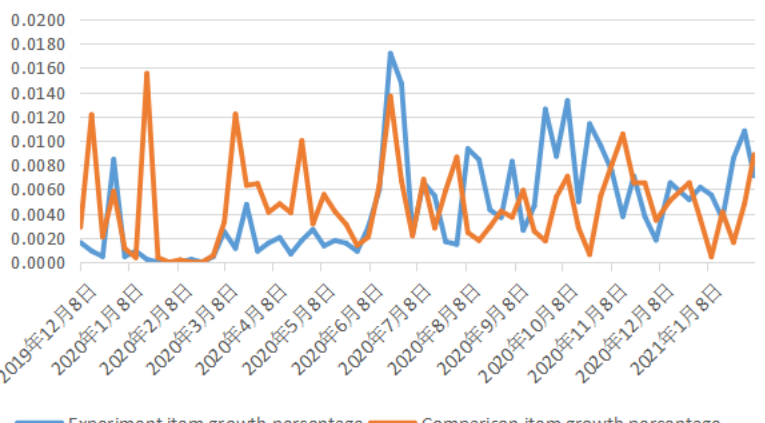

Figure 7. Vacuum cleaner

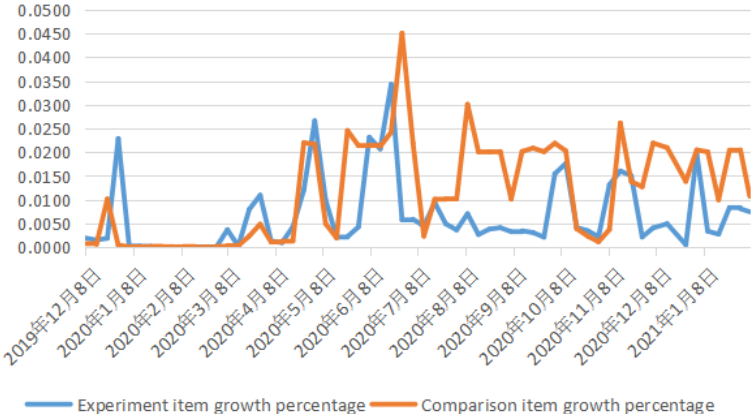

Figure 6. Balance scooter

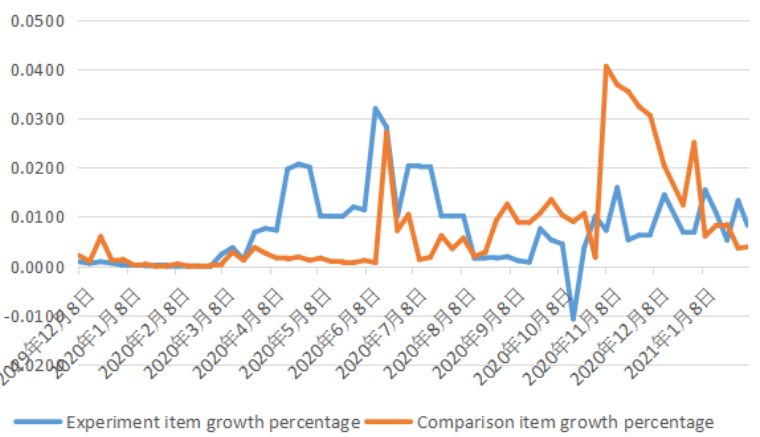

Figure 8. Camera

(3) comparison chart of commodity sales growth on Amazon (Figure 9, Figure 10, Figure 11, and Figure 12).

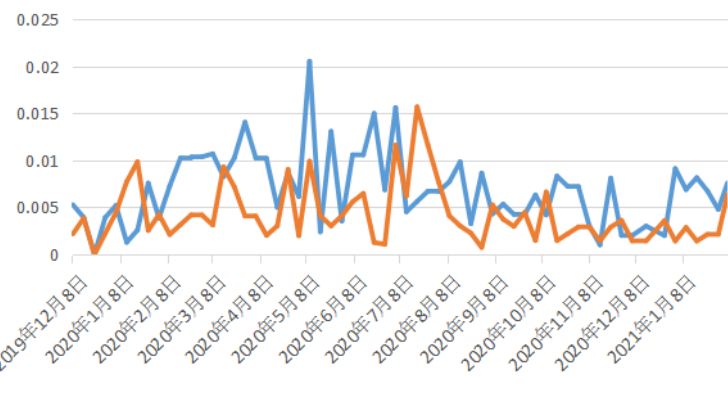

Figure 9. Refrigerator

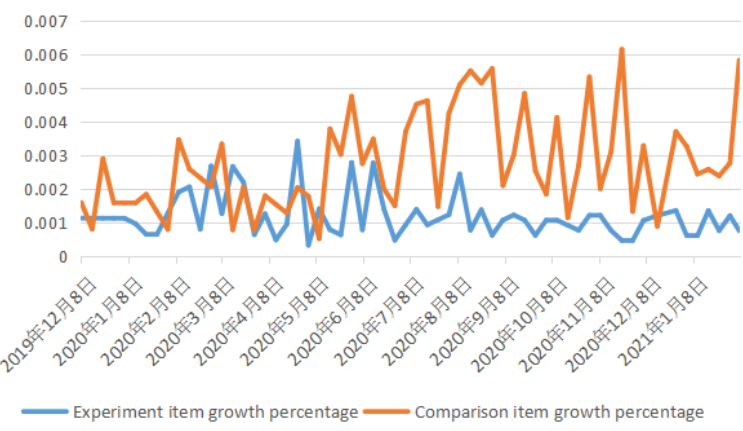

Figure 11. Coffee machine

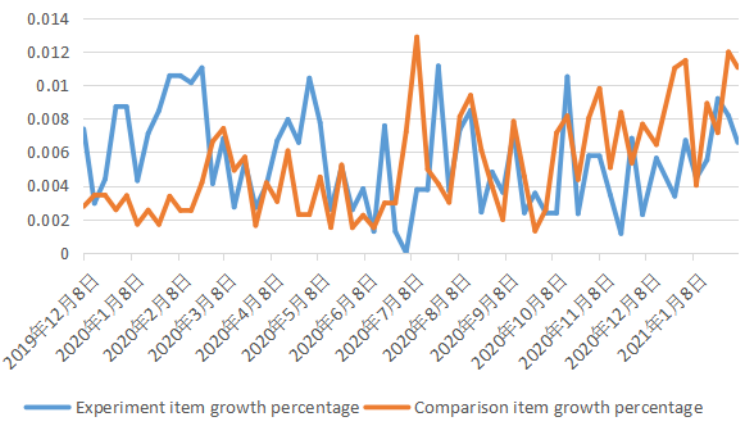

Figure 10. Television

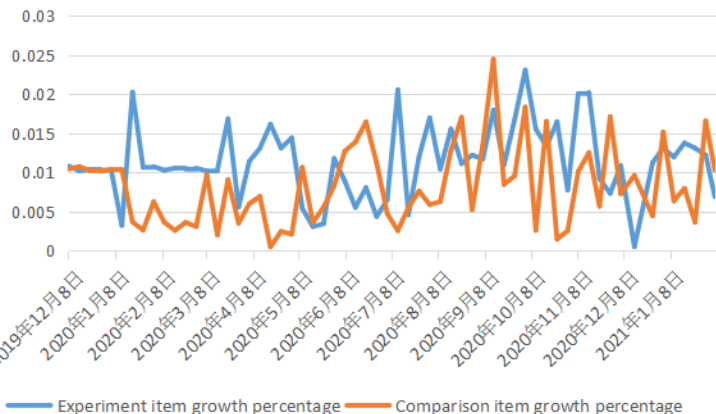

Figure 12. Audio 
From the product data analysis of Taobao, the experimental commodities of massagers, printers, and projectors showed relatively good sales results, but the overall effect of high-priced commodity computers was not as good as the comparison commodity. The marketing effect of the experimental commodities of printers and projectors remained positive, whereas high-priced products had a negative impact. The product marketing data on JD and Amazon were compared and analyzed with the same method, and the following conclusions can be preliminarily obtained:

(1) On Taobao, the false low-price marketing strategy had a certain positive effect on mid-priced and low-priced products, but the marketing effect on high-priced products was not significant. The lowpriced experimental commodities changed over time, and the marketing effect deteriorated. The marketing strategy had a positive impact on mid-priced products continually.

(2) On JD, the false low-price marketing strategy had a relatively good impact on the marketing effect of mid-priced and low-priced products but had little impact on the marketing effect of high-priced products. The low-priced experimental commodities changed over time, but the marketing strategy maintained a positive effect. For mid-priced experimental commodities, the effect of the marketing strategy was not significant.

(3) On Amazon, the false low-price marketing strategy had obvious positive effect on high-priced and low-priced products but had little effect on mid-priced products. The high-priced experimental commodities maintained a positive impact over time, but the low-priced commodities gradually showed a negative impact.

\subsection{Time dimension impact analysis}

The data of the experimental commodities were analyzed in quarterly timeline. The above conclusions were verified, and the impact of product marketing was further analyzed. The sales growth percentages of the experimental commodities on the three e-commerce platforms were calculated on a quarterly basis, and the results are shown in Table 3.

Table 3. Percentage increase in the marketing data of the experimental commodities

\begin{tabular}{|c|c|c|c|c|c|c|c|c|c|c|c|c|}
\hline \multirow[b]{2}{*}{$\begin{array}{l}\text { Time } \backslash \\
\text { Goods }\end{array}$} & \multicolumn{4}{|c|}{ Taobao } & \multicolumn{4}{|c|}{ JD } & \multicolumn{4}{|c|}{ Amazon } \\
\hline & Massager & Lenovo & Projector & Printer & $\begin{array}{c}\text { Balance } \\
\text { scooter }\end{array}$ & $\begin{array}{c}\text { Rice } \\
\text { cooker }\end{array}$ & Camera & $\begin{array}{l}\text { Vacuum } \\
\text { cleaner }\end{array}$ & $\begin{array}{c}\text { Coffee } \\
\text { machine }\end{array}$ & Refrigerator & Television & Audio \\
\hline First season & 0.0115 & -0.0098 & -0.0247 & 0.0049 & 0.0058 & 0.0023 & 0.0024 & 0.0210 & -0.0025 & -0.0123 & 0.0112 & 0.0168 \\
\hline Second quarter & 0.1669 & 0.0306 & 0.0266 & 0.0180 & -0.0116 & 0.0010 & 0.0048 & 0.0371 & -0.0033 & -0.0161 & -0.0156 & 0.0273 \\
\hline Third quarter & 0.0658 & 0.0253 & 0.0221 & 0.0052 & 0.0127 & 0.0044 & -0.0152 & 0.0195 & -0.0108 & 0.0066 & 0.0032 & 0.0351 \\
\hline Fourth quarter & -0.0202 & -0.0138 & 0.0033 & 0.0076 & -0.0110 & -0.0042 & -0.0426 & 0.0299 & 0.0099 & 0.0186 & 0.0169 & -0.0162 \\
\hline
\end{tabular}

The percentage of sales growth changed over different time periods. In the first quarter of 2020, computers and projectors on Taobao showed negative values, balance scooters on JD had a positive effect, refrigerators showed large negative values, while televisions and audios showed large positive values. However, in the second quarter of 2020, Taobao's computers showed large positive values; only balance scooters on JD showed negative values, and on Amazon, only low-priced products (audios) showed a relatively small positive value. In the third quarter of 2020, massagers and Lenovo computers on Taobao showed a positive impact along with balance scooters, rice cookers, and vacuum cleaners on JD; refrigerators and televisions on Amazon also showed positive values. In the fourth quarter of 2020, massagers and Lenovo computers on Taobao had negative values; on JD, only vacuum cleaners showed a 
positive value, the other products showed negative values; on Amazon, refrigerators gradually showed a positive effect.

From the perspective of the time dimension, the impact on Taobao's low-priced products changed from positive to negative, while its medium-priced products maintained a relatively stable positive impact; the impact on medium-priced products on JD gradually showed a negative impact, while its low-priced products maintained a relatively stable positive impact; the impact on high-priced products on Amazon gradually became less, but it still maintained as a positive impact; medium-priced and low-priced products on Amazon were less affected.

The data analysis of the experimental commodities in the time dimension has led to the following conclusions: (1) the impact of low-priced products on Taobao changed from a positive effect to a negative one, and medium-priced products maintained a relatively stable positive impact; (2) the impact of mediumpriced products on JD gradually became negative, but its low-priced products maintained a relatively stable positive impact; (3) the impact on high-priced products on Amazon gradually diminished, but it still maintained a positive impact.

\section{Marketing strategy suggestions}

(1) Ensure the reputation of the business. A false low-price marketing strategy would have different effects on the sales of different commodities. The reputation of a merchant is mainly reflected in the quality of the product, the merchant's marketing strategy, and the delivery speed of goods. Consumers will tend to express their shopping experience through comments. In the process of formulating marketing strategies, businesses need to interact with consumers and pay attention to their emotional changes. A high reputation is the guarantee for increasing the sales of a business. The credibility of a business is the best publicity for a product to attract potential customers.

(2) Combination of short-term profit and long-term profit. The low-price marketing strategy brings varying degrees of short-term sales growth for different types of commodities. In the process of lowering commodity prices, whether the increase of sales increases the profitability is a question that merchants must pay attention to. Merchants need to clarify the types of commodities and set different price ranges for different commodities to ensure short-term profit growth. The low-price marketing strategy also has varying degrees of long-term impact on different types of commodities. Therefore, merchants need to pay attention to both the short-term profit and long-term impact of the low-price marketing strategy on products.

\section{Disclosure statement}

The authors declare that there is no conflict of interest.

\section{References}

[1] Manzur E, Olavarrieta S, Hidalgo-Campos P, et al., 2013, Store Price Promotion Strategies: An Empirical Study from Chile. Academia Revista Latinoamericana de Administración, 26(3): 356-372.

[2] Dominique-Ferreira S, Vasconcelos H, Proença JF, 2016, Determinants of Customer Price Sensitivity: An Empirical Analysis. Journal of Services Marketing, 30(3): 327-340.

[3] Sun X, Tian P, Zhao C, 2013, Pricing Strategy Selection based on Quality-price Competition under Consumer Heterogeneity. Journal of Systems Management, 2013(03): 349-357.

[4] Zhang Z, 2012, Consumer Behavior, Tsinghua University Press, Beijing, 310-329. 
[5] Zhou B, 2013, Consumer Behavior, Tsinghua University Press, Beijing, 137-175. 